\title{
Thermal Stability Testing of Fischer-Tropsch Fuel and Various Blends With Jet A, as well as Aromatic Blend Additives
}

\author{
J. Klettlinger, NASA Glenn Research Center, R. Rich, Undergraduate Student Research Program \\ Intern at NASA Glenn Research Center, C. Yen, University of Toledo, and A. Surgenor, NASA Glenn \\ Research Center
}

\begin{abstract}
-
Fischer-Tropsch (F-T) jet fuel composition differs from petroleum-based, conventional commercial jet fuel because of differences in feedstock and production methodology. FischerTropsch fuel typically has a lower aromatic and sulfur content and consists primarily of iso and normal parafins. The ASTM D3241 specification for Jet Fuel Thermal Oxidation Test (JFTOT) break point testing method was used to test the breakpoint of a baseline conventional Jet $\mathrm{A}$, a commercial grade F-T jet fuel, and various blends of this F-T fuel in Jet $A$. The testing completed in this report was supported by the NASA Fundamental Aeronautics Subsonics Fixed Wing Project.
\end{abstract}

Index Terms-Alternative Fuel, Break Point Testing, FischerTropsch Fuel, Thermal Stability

\section{INTRODUCTION}

$F_{\text {firen }}$ ischer-Tropsch (F-T) fuel is a synthetic fuel derived from syn-gas. The syn-gas can come from various resources such as natural gas, coal, biomass, or even garbage. The use of Fischer-Tropsch fuel could have the added benefit of reducing the nation's energy reliance on foreign supply of petroleum based fuel. Fischer-Tropsch jet fuel composition differs from the petroleum based, conventional commercial jet fuel because of differences in feedstock and production methodology. F-T is generally composed of iso- and nalkanes, with little aromatic content ${ }^{1}$. These compositional differences provide some benefits and drawbacks for the use in jet engines.

In comparison to petroleum-derived fuels, F-T has shown increased thermal-oxidative stability and significantly lower particulate matter combustion emissions ${ }^{1}$. F-T jet fuel is expected to be more stable than conventional jet fuel at elevated temperatures, thus offering a potentially cleaner burning fuel with better thermal stability characteristics. One method to quantify the fuel's oxidative thermal stability is to measure the fuel's breakpoint in accordance with ASTM D3241 specification test known as Jet Fuel Thermal Oxidation Test (JFTOT) ${ }^{2}$.

This work was supported by the NASA Fundamental Aeronautics Subsonics Fixed Wing Project.
JFTOT assesses fuel thermal degradation by two means: one by the heated tube's discoloration due to hydrocarbon coating, the other by determining a filter pressure drop (dp) due to particulate formation. Aerated fuel flows at $3 \mathrm{cc} / \mathrm{min}$ over an electrically heated tube at a preset temperature for 150 min. At the end of the test, the tube is removed from the test stand and visually examined. The tube is inserted into a Visual Tube Rater (VTR) which is an internally lit black box consisting of a standard ASTM color chart. The tube is optically compared to the color chart and is assigned a color number ranging from 1 to 4 ( 1 is metallic silver, 2 is slightly tan, 3-4 are brown). A tube color of 3 or less constitutes a pass. Fuel degradation forms particulates which are collected on a filter, and leads to a higher filter dp over the test period. $25 \mathrm{mmHg}$ is the maximum pressure drop permitted over the full $150 \mathrm{~min}$ test for a fuel to pass the test. Both criteria, tube color $(<=3)$ and $\mathrm{dp}(<=25 \mathrm{mmHg})$, must be met in order to pass the JFTOT. To determine the fuel's breakpoint, the fuel is tested at $5{ }^{\circ} \mathrm{C}$ increments from $260{ }^{\circ} \mathrm{C}$. Breakpoint is defined as the highest temperature at which the fuel passes the JFTOT.

One of the drawbacks of Fischer-Tropsch fuel is that the lubricity and seal-swell may need to be improved before pure F-T jet fuel is approved ${ }^{1}$. Aromatics are known to improve these seal-swell characteristics as well as increase engine particulate emissions ${ }^{1}$. Previous studies have been completed by the Air Force Research Laboratory (AFRL) for the feasibility of adding aromatic solvents in order to meet these seal-swell requirements ${ }^{1}$. AFRL studies showed that the particulate matter emissions increased as the aromatic molecular weight and concentration increased ${ }^{1}$. They attributed these phenomena to the increased soot precursors in the aromatic blend additions to the fuel ${ }^{1}$.

In another study, particle mass emissions were measured with the TEOM for various concentrations of aromatic blend added to synthetic fuel. This study showed that the particle mass concentration increased with increasing aromatic concentration $^{3}$. This indicates that aromatic content may increase the particulate formation, thus affecting the thermal stability. It was previously found that aromatics have little effect on key gaseous emissions such as: $\mathrm{CO}, \mathrm{CO}_{2}$, and $\mathrm{No}_{\mathrm{x}}{ }^{3}$.

It has also been shown that the seal-swell of nitrile rubber was increased mostly with addition of alkyl-napthalenes as opposed to alkylbenzenes, which could have been because of increased polarity in larger aromatics ${ }^{1}$. 
One way of increasing the aromatic content and the sealswell characteristics is to blend the F-T fuel with conventional petroleum derived fuel. This study explores the use of blending F-T with conventional Jet-A and how these blends affect the thermal stability of this fuel. Furthermore, the addition of aromatic blends or feedstock may be required to achieve the seal-swell characteristics that are necessary. This paper further explores the thermal stability of Fischer-Tropsch fuel and how the increase in aromatic concentration affects its thermal stability.

\section{TECHNICAL WORK PREPARATION}

The thermal stability test laboratory located in the B109 Alternative Fuels Research Laboratory ${ }^{4}$ houses a Hot Liquid Process Simulator (HLPS), model HLPS-400 manufactured by Alcor ${ }^{5}$. The HLPS is designed to determine jet fuel breakpoint according to the test method outlined in ASTM D 3241 ${ }^{2}$. The HLPS unit is located inside a fume hood (see Fig. 1) and requires water for cooling, gaseous nitrogen to pressurize the reservoir and Zero Air to aerate the fuel before conducting a test. The HLPS unit is connected to a PC which is used for data acquisition and control purposes.

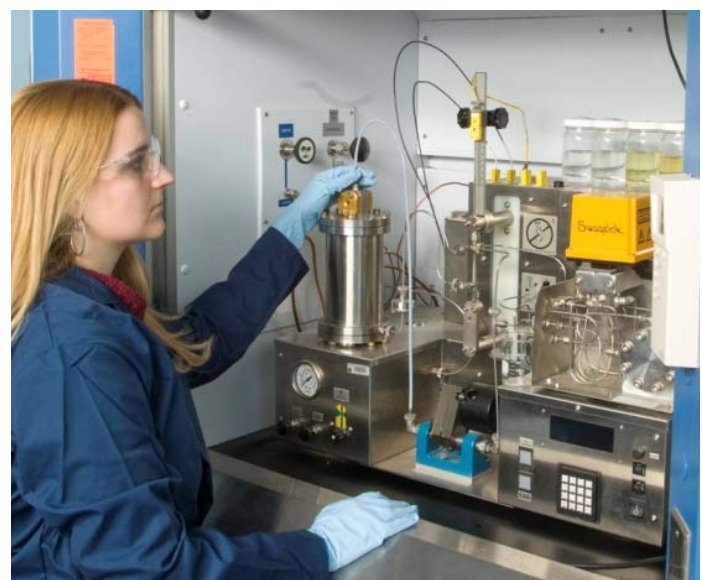

Figure. 1. Hot Liquid Process Simulator inside of fume hood in room 102.

The HLPS components are mainly constructed of stainless steel. The HLPS is capable of testing fuel thermal stability at temperatures up to $650{ }^{\circ} \mathrm{C}$. Various types of heater tubes can be used in order to reach temperature requirements for each individual test. JFTOT tests require the use of an aluminum tube, which has a limit of $380^{\circ} \mathrm{C}$. Steel or stainless steel tubes are also available for tests needing to reach higher temperatures of up to $650{ }^{\circ} \mathrm{C}$. The fuel flow rate can be varied from 0.25 to $5 \mathrm{~mL} / \mathrm{min}$ for each test.

The HLPS was used to evaluate the breakpoint temperature for pure Jet A, pure F-T jet fuel, and various blends (by volume) of these two fuels $(10,30,50,70$, and 90 percent F-T fuel). JFTOT breakpoint testing procedures were followed except at higher temperatures, where a steel tube was used. Figure 2 shows the diagram of the HLPS. A fuel sample was loaded into a stainless steel reservoir. The fuel reservoir was pressurized to 500 psig with gaseous nitrogen and set to a constant flow rate of $3 \mathrm{cc} / \mathrm{min}$.

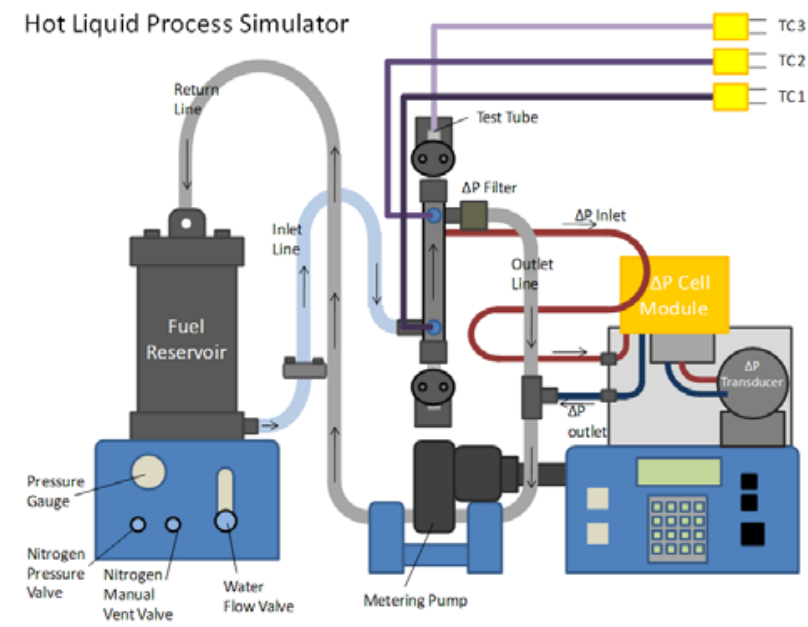

Figure. 2. Hot Liquid Process Simulator Diagram

The HLPS pumped the fuel through a resistance heated tube-in-shell heat exchanger while monitoring flow, temperature, and pressure. At the outlet of the reservoir, the fuel flowed through a pre-filter and then over the heated tube. The heated tube was ramped up to a target temperature with minimal temperature variation (specified in test procedure) for each test, providing a stable "soak" temperature. At the outlet of the heated tube, a small disposable filter was in place to capture particulates which were formed during the heating process. The HLPS analyzer measured and recorded the pressure drop over this filter throughout the test duration. Figure 3 shows the diagram of the tube apparatus, which shows the fuel flow and outlet filter construction.
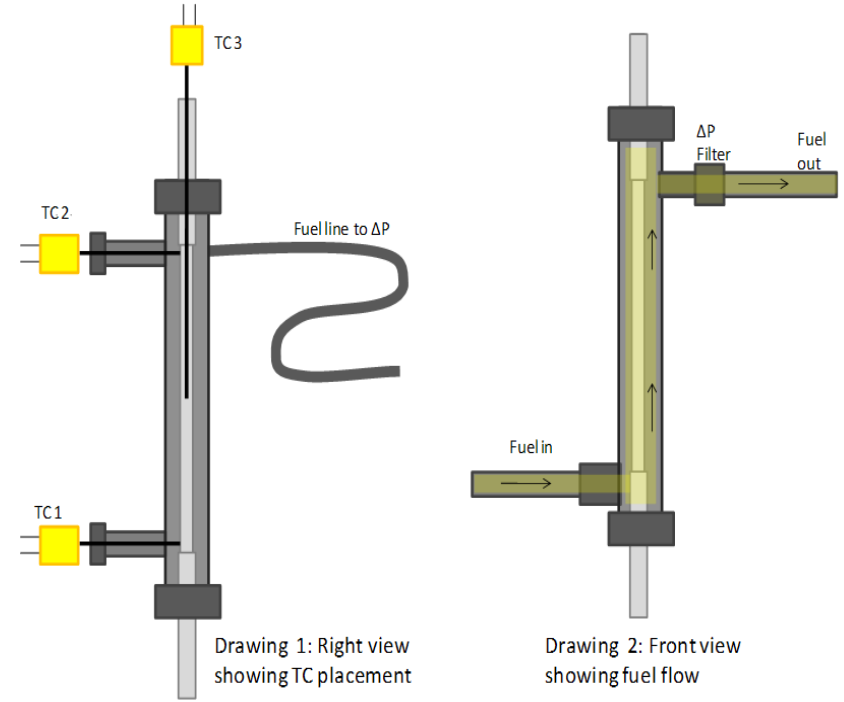

Figure. 3. Hot Liquid Process Simulator Tube Graphic

Both criteria for the JFTOT can be evaluated using the HLPS. Each HLPS run result was ranked as pass/fail. Each test required approximately $500 \mathrm{~mL}$ of fuel; however multiple tests are required to determine the breakpoint temperature. If a test was completed with a "pass" rating on tube color and pressure drop, a new batch of the same fuel was retested at a higher temperature at intervals of $5{ }^{\circ} \mathrm{C}$. This process was repeated until a failure occurred. 


\section{Results and Discussion}

Fuel analysis results on F-T and Jet A fuel are shown in Table I.

TABLE I

FISCHER-TROPSCH AND JET A FUEL ANALYSIS RESULTS

\begin{tabular}{|l|c|c|}
\hline \multicolumn{1}{|c|}{ Test } & F-T & Jet A \\
\hline Total Acid Number $(\mathrm{mg} \mathrm{KOH} / \mathrm{g})$ & 0.002 & 0.00 \\
\hline Aromatics $(\%$ vol) & 0.0 & 19 \\
\hline Mercaptan Sulfur $(\%$ mass) & 0.000 & 0.000 \\
\hline Total Sulfur $(\%$ mass) & 0.00 & 0.0 \\
\hline Distillation & & \\
\hline Initial Boiling Point $\left({ }^{\circ} \mathrm{C}\right)$ & 149 & \\
\hline $10 \%$ Recovered $\left({ }^{\circ} \mathrm{C}\right)$ & 162 & 180 \\
\hline $20 \%$ Recovered $\left({ }^{\circ} \mathrm{C}\right)$ & 163 & \\
\hline $50 \%$ Recovered $\left({ }^{\circ} \mathrm{C}\right)$ & 168 & 212 \\
\hline $90 \%$ Recovered $\left({ }^{\circ} \mathrm{C}\right)$ & 184 & 251 \\
\hline End Point $\left({ }^{\circ} \mathrm{C}\right)$ & 196 & \\
\hline Residue $(\%$ vol) & 0.9 & 1.3 \\
\hline Loss $(\%$ vol) & 0.4 & 0.9 \\
\hline Flash Point $\left({ }^{\circ} \mathrm{C}\right)$ & 44 & 51 \\
\hline API Gravity at $60{ }^{\circ} \mathrm{F}$ & 60.5 & \\
\hline Freezing Point $\left({ }^{\circ} \mathrm{C}\right)$ & -55 & -48 \\
\hline Viscosity at $-20{ }^{\circ} \mathrm{C}\left(\mathrm{mm}{ }^{2} / \mathrm{s}\right)$ & 2.6 & 5.2 \\
\hline Net Heat of Combustion $(\mathrm{MJ} / \mathrm{kg})$ & 44.2 & \\
\hline Hydrogen Content $(\% \mathrm{mass})$ & 15.6 & \\
\hline Smoke Point $(\mathrm{mm})$ & 40.0 & 21 \\
\hline Copper Strip Corrosion $\left(2 \mathrm{~h}\right.$ at $\left.100{ }^{\circ} \mathrm{C}\right)$ & $1 \mathrm{a}$ & \\
\hline Thermal Stability at $260{ }^{\circ} \mathrm{C}$ & & \\
Change in Pressure $(\mathrm{mmHg})$ & 0 & 1 \\
\hline Tube Deposit Rating, Visual & 1 & 0 \\
\hline Existent Gum $(\mathrm{mg} / 100 \mathrm{~mL})$ & $<1$ & 0.2 \\
\hline Particulate Matter $(\mathrm{mg} / \mathrm{L})$ & 0.4 & 0.2 \\
\hline Filtration Time $(\mathrm{min})$ & 2 & \\
\hline Water Reaction Interface Rating & 1 & 1 \\
\hline FSII $(\%$ vol) & 0.00 & 0.00 \\
\hline Conductivity $(\mathrm{pS} / \mathrm{m})$ & 217 & 10 \\
\hline Lubricity Test $(\mathrm{BOCLE}) \mathrm{Wear} \mathrm{Scar}(\mathrm{mm})$ & 0.75 & \\
\hline Net Heat of Combustion $(\mathrm{MJ} / \mathrm{kg})$ & 44.0 & 43.2 \\
\hline Workmanship & Pass & Pass \\
\hline & & \\
\hline & & \\
\hline & & \\
\hline
\end{tabular}

Figure 4 shows the breakpoint measurements for Jet A, F-T jet fuel, and blended mixtures of Jet A and F-T jet fuel. The different colored bars are repeat testing at the same blend of fuel. Results of blended fuels indicate that the fuel thermal stability break point is not linearly related to the fuel blending ratio. Results show that the thermal stability of a 50 percent Jet $\mathrm{A} / 50$ percent $\mathrm{F}-\mathrm{T}$ fuel blend is consistent with that of less stable Jet A fuel. Even a sample of 30 percent Jet A/70 percent F-T blend does not result in a significantly higher breakpoint. A major difference in break point data is first noticed at a mixture of 90 percent F-T fuel. Fuel blends with less than 90 percent F-T fuel have fuel breakpoints consistent with that of less stable Jet A fuel. This indicates that the breakpoint depends on degradation of minor fuel components and is not a fuel bulk property. Three repeated tests on the same fuel/fuel blends confirmed that the results were reproducible with a maximum of $10^{\circ} \mathrm{C}$ variation.

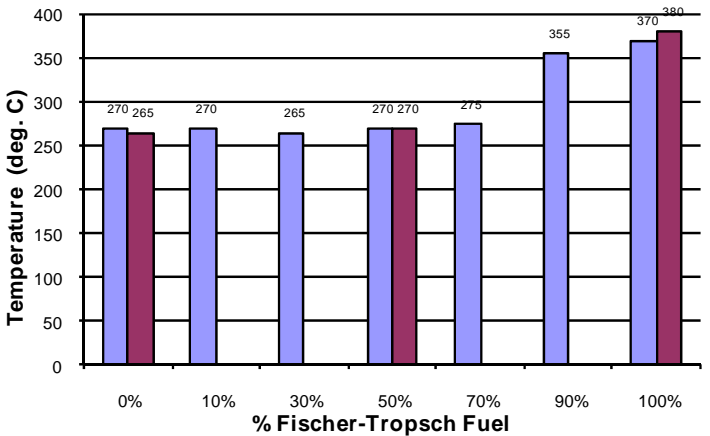

Figure 4.-Thermal stability breakpoint data for F-T Jet fuel and blended mixtures in Jet A fuel.

It is likely that Jet A produced a higher quantity of particles or the particles produced were larger. After testing, sample tubes for both Jet A and F-T Jet fuel were cut apart and examined with an optical microscope. Photographs of the heated tube surfaces are shown in Figure 5. It appears that larger particles are found on the heated tube surface with Jet A in comparison to F-T fuel, although further investigation is required to validate. The material properties of the tube surface may also make a difference. Figure 5 shows major differences in the aluminum tube surface versus the steel tube surface, both tested with F-T fuel. This may indicate that the fuel interacts with the tube surface differently, thus requiring a different "tube color" or tube coating rating when different tube types are used.

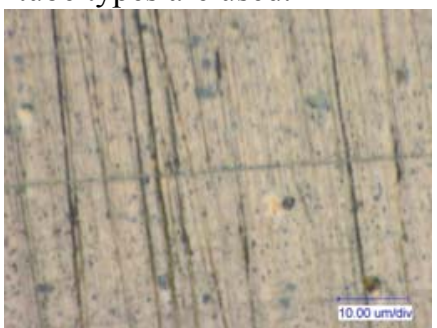

Jet A-aluminum tube (passed)

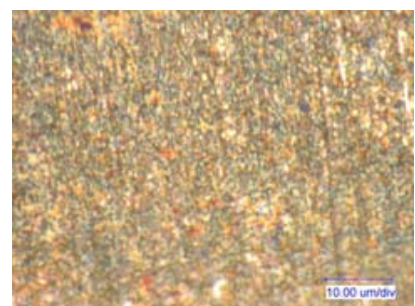

F-T fuel-aluminum tube (passed)

Figure 5.-Optical images of tubes after testing.

Optical images in Figure 5 indicate that there may be major differences between the tube surface composition and how the particulates form on the surface of the tube. These surface differences may affect the tube discoloration upon heating and its subsequent failure ranking; a different scale may be needed for measuring the tube color failure of a steel tube versus an aluminum tube. Since the VTR is designed to test for JFTOT 
color schemes for aluminum tubes, it may or may not be a valid test for the steel tubes because of the difference in tube properties. Figure 6 shows the optical images of clean tube surfaces at magnifications of 1 and $5 \mathrm{kx}$.

The clean tube optical images show the different surface characteristics. This observation leads us to believe that heated fuel may react differently on the steel tube versus the aluminum tube.

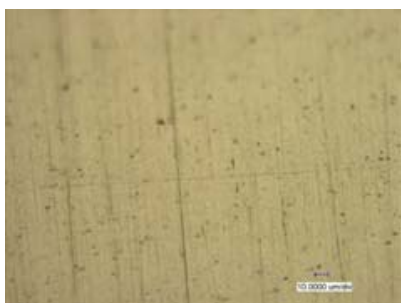

Clean aluminum tube $1 \mathrm{kx}$

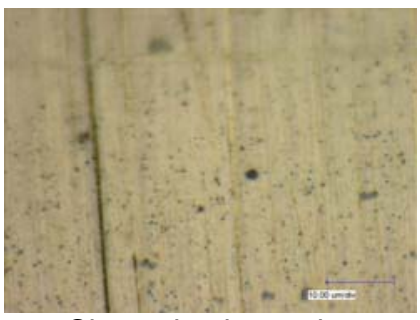

Clean aluminum $5 \mathrm{kx}$

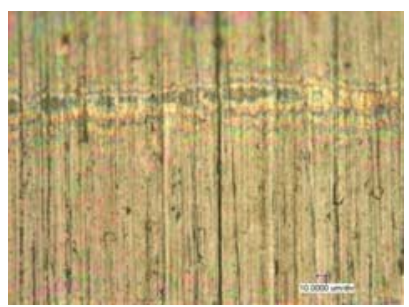

Clean steel tube $1 \mathrm{kx}$

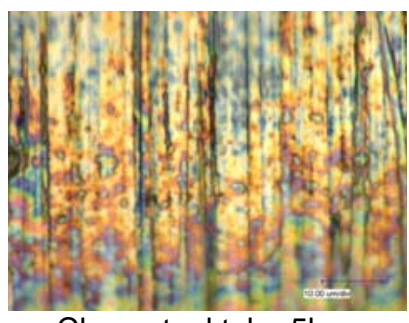

Clean steel tube $5 \mathrm{kx}$
Figure 6.-Optical images of clean tube surfacescomparison of aluminum to steel.

Figure 7 displays some previous data shown in Figure 4 but indicates the type of failure. It should be noted that petroleum based $(100 \%)$ Jet A breakpoints were reached because of high filter pressure drop after the heated tube. The $100 \% \mathrm{~F}-\mathrm{T}$ fuel breakpoints were not triggered by pressure drop, but by tube surface discoloration. F-T fuel seems to produce less particulate at elevated temperatures in comparison to the conventional Jet A. Typical JFTOT test only requires one of the criteria tests to fail for the complete test to be a failure. Since the validity of color rating on the steel tube is unknown, this may indicate that F-T fuel has a higher breakpoint temperature than observed per criteria stipulated in ASTM D 3241. Since JFTOT is a standardized test method developed and intended to be used with aluminum tubes, a new standardized method may be required for testing at temperatures above $380^{\circ} \mathrm{C}$.

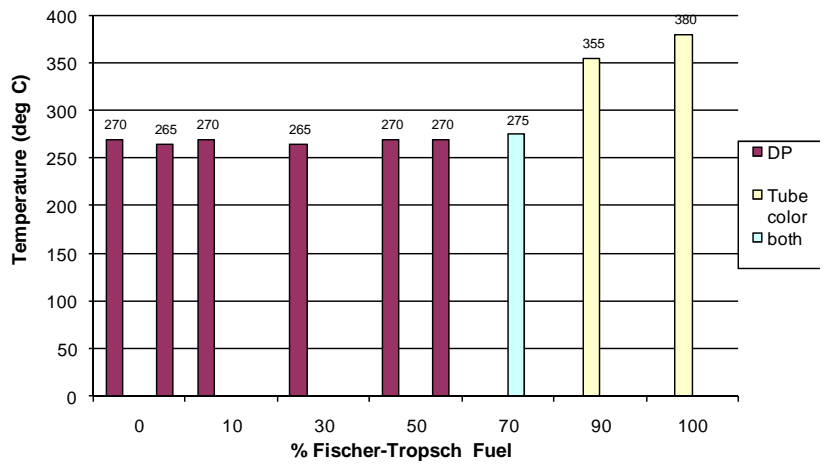

Figure 7.-F-T fuel thermal stability breakpoint based on type of failure.

The HLPS was also used to evaluate the effect of a heightened aromatic content on pure F-T jet fuel. This heightened aromatic content was achieved by mixing the pure F-T jet fuel with an aromatic blend, which was formed using a combination of different aromatic solvents. The two quantities were calculated depending on what the target aromatic content was, and mixed together to create a fuel sample. The aromatic blend information is included in Table II, which is the same additives used in the study completed by AFRL ${ }^{1}$.

TABLE II

AROMATIC BLEND ADDITIVE INFORMATION

\begin{tabular}{|c|c|c|}
\hline \multicolumn{3}{|c|}{ Aromatic 100 Fluid (Hydrocarbon) } \\
\hline Properties & Test Methods & $\begin{array}{l}\text { Sales } \\
\text { Specifications }\end{array}$ \\
\hline Appearance & Visual & Pass \\
\hline Aromatics Content (vol. \%) & ASTM D 1319 & $98.0 \mathrm{~min}$ \\
\hline Color (Saybolt Units) & ASTM D 156 & $30 \mathrm{~min}$ \\
\hline Distillation & ASTM D 86 & \\
\hline IBP $\left({ }^{\circ} \mathrm{C}\right)$ & & $154 \mathrm{~min}$ \\
\hline $\mathrm{DP}\left({ }^{\circ} \mathrm{C}\right)$ & & $174 \max$ \\
\hline Flash Point $\left({ }^{\circ} \mathrm{C}\right)$ & ASTM D 56 & $42 \mathrm{~min}$ \\
\hline Kauri-Butanol Value & ASTM D 1133 & $90 \mathrm{~min}$ \\
\hline $\begin{array}{l}\text { Specific Gravity @ } \\
15.6 / 15.6{ }^{\circ} \mathrm{C}\end{array}$ & ASTM D 4052 & $0.868-0.878$ \\
\hline \multicolumn{3}{|c|}{ Ultra Low Napthelene Aromatic 150 Fluid (Hydrocarbon) } \\
\hline Appearance & Visual & Pass \\
\hline Aromatics Content (vol. \%) & ASTM D 1319 & $95 \mathrm{~min}$ \\
\hline Color (Saybolt Units) & ASTM D 156 & $27 \mathrm{~min}$ \\
\hline Distillation & ASTM D 86 & \\
\hline IBP $\left({ }^{\circ} \mathrm{C}\right)$ & & $175 \mathrm{~min}$ \\
\hline $\mathrm{DP}\left({ }^{\circ} \mathrm{C}\right)$ & & $215 \max$ \\
\hline Flash Point $\left({ }^{\circ} \mathrm{C}\right)$ & ASTM D 56 & $62 \mathrm{~min}$ \\
\hline Naphthalene Content (wt.\%) & $\mathrm{GC}$ & $0.1 \max$ \\
\hline $\begin{array}{l}\text { 1,2,4 Trimethyl Benzene } \\
\text { (wt.\%) }\end{array}$ & $\mathrm{GC}$ & $0.9 \max$ \\
\hline \multicolumn{3}{|c|}{ Aromatic 200 Fluid (Hydrocarbon) } \\
\hline Properties & Test Methods & $\begin{array}{l}\text { Sales } \\
\text { Specifications }\end{array}$ \\
\hline Aniline Point $\left({ }^{\circ} \mathrm{C}\right)$ & $\begin{array}{l}\text { ASTM D } 611 \text { (Mixed } \\
\text { Aniline Point) }\end{array}$ & $\# 7-18$ \\
\hline Appearance & Visual & Pass \\
\hline Aromatics Content (vol. \%) & ASTM D 1319 & $98.0 \mathrm{~min}$ \\
\hline Color (ASTM Units) & ASTM D 1500 & $1.0 \max$ \\
\hline Distillation & ASTM D 86 & \\
\hline IBP $\left({ }^{\circ} \mathrm{C}\right)$ & & $220 \mathrm{~min}$ \\
\hline $\mathrm{DP}\left({ }^{\circ} \mathrm{C}\right)$ & & $293 \max$ \\
\hline Flash Point $\left({ }^{\circ} \mathrm{C}\right)$ & ASTM D 93 & $95 \min$ \\
\hline $\begin{array}{l}\text { Specific Gravity @ } \\
15.6 / 15.6^{\circ} \mathrm{C}\end{array}$ & ASTM D 4052 & $0.99-1.01$ \\
\hline
\end{tabular}

In order to calculate the amount of aromatic blend to add to the current fuel, the current fuel aromatic content has to be integrated into the calculations. Since the HLPS requires a specified amount of fuel, the total fuel was held constant at $600 \mathrm{~mL}$ for each run. The following equations were used in determining the volume of aromatic blend to add to the fuel sample. With the intention of limiting variables, the aromatic blend was added to fuel which came from the same fuel tank. 
$V_{T}:$ Total Volume

$V_{F}:$ Volume of fuel

$V_{A}$ :Volumeof Aromatic Blend

$V_{T}=V_{F}+V_{A}$

$x: t$ arg et aromatic content

$y$ : fuel aromatic content

$$
x\left(V_{T}\right)=y\left(V_{F}\right)+1\left(V_{A}\right)
$$

For example, the total volume of fuel $\left(\mathrm{V}_{\mathrm{T}}\right)$ was set to $600 \mathrm{~mL}$ and the aromatic content $(\mathrm{y})$ of the fuel was $1.6 \%$. To find the quantity of the fuel needed $\left(\mathrm{V}_{\mathrm{F}}\right)$, the target aromatic content (x) was multiplied by the target volume $\left(\mathrm{V}_{\mathrm{T}}\right)$. Then the target volume $\left(\mathrm{V}_{\mathrm{T}}\right)$ was subtracted. The answer was then divided by the current aromatic content (y) minus one. For instance, with the target volume at $600 \mathrm{~mL}$ and the target aromatic content at $5 \%$, the equation would be:

$$
\begin{aligned}
& V_{T}=600 \\
& V_{F} \text { : Volume of fuel } \\
& V_{A}=V_{T}-V_{F}=600-V_{F} \\
& x=5 \% \\
& y=1.6 \% \\
& 5 \%(600)=1.6 \%\left(V_{F}\right)+1\left(600-V_{F}\right) \\
& \text { Solve for } V_{F} \text { : } \\
& V_{F}=[(0.05 * 600)-600] /(0.016-1)=\sim 589 \mathrm{~mL}
\end{aligned}
$$

Then, to find the volume of the aromatic blend $\left(\mathrm{V}_{\mathrm{A}}\right)$ needed, the volume of fuel that has been found $\left(\mathrm{V}_{\mathrm{F}}\right)$ was subtracted from the total volume $\left(\mathrm{V}_{\mathrm{T}}\right)$. Once $\mathrm{V}_{\mathrm{F}}$ and $\mathrm{V}_{\mathrm{A}}$ were found, the two quantities were measured out, using a graduated cylinder. The aromatic blend $\left(\mathrm{V}_{\mathrm{A}}\right)$ was poured into the fuel $\left(\mathrm{V}_{\mathrm{F}}\right)$ and then stirred. From there, the blended fuel was filtered normally, and the rest of the experiment carried out.

$$
V_{A}=V_{A}=V_{T}-V_{F}=600-V_{F}=600-589=\sim 11 \mathrm{~mL}
$$

JFTOT testing procedures were followed using the same procedures as previous experiments. Each test required approximately $500 \mathrm{~mL}$ of fuel, so $600 \mathrm{~mL}$ were used as a failsafe, in case of a leak. Once a test had been completed, if it passed, the aromatic content was increased for the next fuel sample. The testing began with a fuel that was $0.2 \%$ aromatic, and then increased to a fuel that was $1.6 \%$ aromatic. These fuels were F-T fuels alone, without any added aromatics. From that point, the aromatic content was increased to $5 \%$, and each passing test was increased in increments of $1 \%$ until a failure.

Upon reaching a sample that failed, a breakpoint test sequence was put into effect. This process included lowering the temperature at which a test of the same percent aromatic content fuel sample was conducted, until a pass occurred. Once a passing test was achieved, this was considered to be the breakpoint temperature.

Figure 8 shows preliminary data on a F-T fuel that was blended with aromatic additive. The preliminary data was all ran at $380^{\circ} \mathrm{C}$ and shows a pass $\mathrm{dP}$ rating via JFTOT procedures up to $10 \%$ aromatic content in F-T fuel.

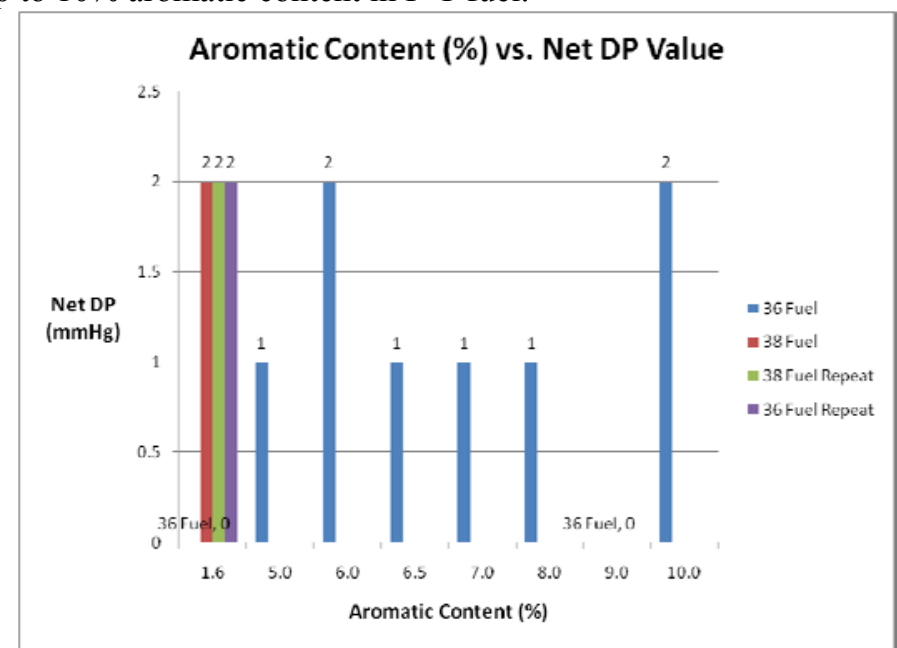

Figure 8: Aromatic Content compared to Net DP Value using the JFTOT method.

Figure 9 shows the tube color data collected via JFTOT on the same F-T fuel. This shows a failure based on tube color at $10 \%$ aromatic blend, although further investigation and repeat data is being collected at this time.

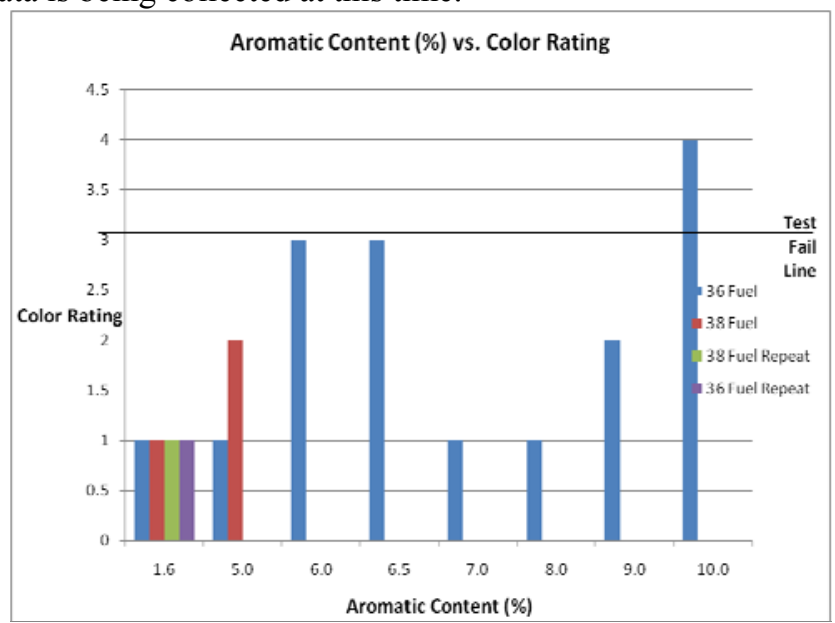

Figure 9: F-T fuel aromatic content in comparisson to tube color rating.

Further investigation was carried out on the $10 \%$ aromatic content fuel to determine the breakpoint. Figure 10 shows the break point tube color data collected on a F-T fuel with $10 \%$ aromatics. It is interesting to note that the test failed at $335^{\circ} \mathrm{C}$ and passed at $300^{\circ} \mathrm{C}$, so based on tube color rating only, the breakpoint would be $300^{\circ} \mathrm{C}$. Figure 11 shows the break point 
$\mathrm{dP}$ rating collected using JFTOT procedures. The fuel shows a pass at all temperatures. This outcome is consisstent with previous data shown in Figure 8 and Figure 9 which showed a failure only based on tube color.

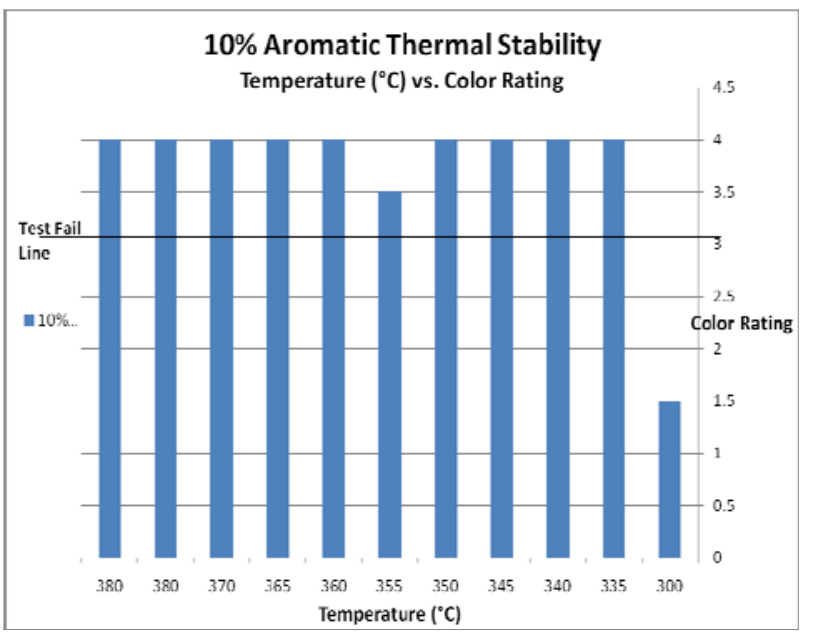

Figure 10: F-T fuel with $10 \%$ aromatic content JFTOT tube color rating in comparisson to test temperature

\section{ACKNOWLEDGMENT}

We would like to express our special appreciation to NASA Fundamental Aeronautics Subsonics Fixed Wing Project for funding this research, Laura Acosta, Summer Intern from Ohio State University, for completing some of the thermal stability tests, Dr. Tim Edwards for providing the fuel and fuel analysis data, and David Hull for tube surface optical imaging.

\section{REFERENCES}

1. DeWitt, M. J.; Corporan, E.; Graham, J.; Minus, D., Effects of Aromatic Type and Concentration in Fischer-Tropsch Fuel on Emissions Production and Material Compatibility. Energy \& Fuels 2008, 22 (4), 2411-2418.

2. ASTM, "Standard Test Method for Thermal Oxidation Stability of Aviation Turbine Fuels (JFTOT Procedure)". In Standard D3241, ASTM International, West Conshohocken, PA, 2003, 2008.

3. Orvin Monroig, E. C., Matthew DeWitt, Ben Mortimer, David Ostdiek, and Matt Wagner, EFFECTS OF JET FUEL AROMATIC CONCENTRATION ON THE EMISSIONS OF A T63 ENGINE. American Chemical Society 2005, Fuel Chem. (50), 335-337.

4. Surgenor, A., Tomsik, T., Klettlinger, J., Nakley, L., Alternative Fuels Research Facility. NASA/TM 2010, 2010-216082.

5. Alcor-PAC, Hot Liquid Process Simulator (HLPS 400) User's Manual Rev. B Oct. 2003

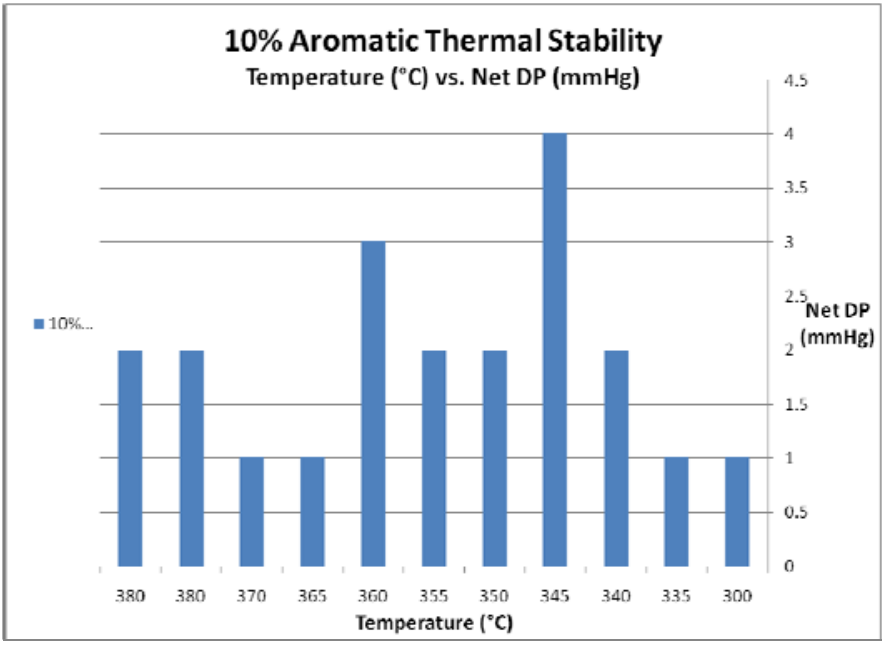

Figure 11: F-T fuel with 10\% aromatic content JFTOT dP rating in comparisson to test temperature

\section{Summary and Conclusions}

A conventional jet fuel, Jet A, was tested as a baseline fuel and its breakpoint was determined to be $270{ }^{\circ} \mathrm{C}$. The breakpoint for F-T jet fuel was determined using a F-T fuel made by a natural gas feed stock (Gas to Liquid- GTL process) and was determined to be at least $370{ }^{\circ} \mathrm{C}$. The F-T based jet fuel proves to be more thermally stable than the conventional Jet A with a breakpoint that is at least $100^{\circ} \mathrm{C}$ higher than Jet A. Optical images have given insight to possible testing differences in Jet A and F-T breakpoint data. This may indicate that the fuel interacts with the tube surface differently, thus requiring a new tube color rating when using tube types other than aluminum. This would require the modification to the standardized test method or a new test method would need to be created for testing thermal stability at temperatures above $380^{\circ} \mathrm{C}$. 